\title{
Commercial Application of In-Space Assembly
}

\author{
John Lymer ${ }^{1}$, Mark Hanson², Al Tadros ${ }^{3}$, Joel Boccio ${ }^{4}$, Bruno Hollenstein ${ }^{5}$, Ken Emerick ${ }^{6}$ \\ Space Systems Loral, Palo Alto, CA 94303, USA \\ Sean Doughtery ${ }^{7}$ \\ MDA US Systems, Boulder, CO, 80301, USA
}

\author{
Bill Doggett ${ }^{8}$, John T. Dorsey ${ }^{9}$, Bruce D. King ${ }^{10}$, and Lynn Bowman ${ }^{11}$ \\ NASA, Langley Research Center, Hampton, VA 23681, USA
}

In-Space assembly (ISA) expands the opportunities for cost effective emplacement of systems in space. Currently, spacecraft are launched into space and deploy into their operational configuration through a carefully choreographed sequence of operations. The deployment operation dictates the arrangement of the primary systems on the spacecraft, limiting the ability to take full advantage of launch vehicles volume and mass capability. ISA enables vastly different spacecraft architectures and emplacement scenarios to be achieved, including optimal launch configurations ranging from single launch and assembly to on-orbit aggregation of multiple launches at different orbital locations and times. The spacecraft can be visited at different orbital locations and times to effect expansion and maintenance of an operational capability. To date, the primary application of ISA has been in large programs funded by government organizations, such as the International Space Station. Recently, Space Systems Loral (SSL) led a study funded by the Defense Advanced Research Projects Agency (DARPA), called Dragonfly, to investigate the commercial applicability and economic advantages of ISA. In the study, it was shown that ISA enables SSL to double the capability of a commercial satellite system by taking advantage of alternate packaging approaches for the reflectors. The study included an ultra-light-weight robotic system, derived from Mars manipulator designs, to complete assembly of portions of the antenna system using a tool derived from DARPA orbital express and National Aeronautics and Space Administration (NASA) automated structural assembly experience. The mechanical connector that enables robotic ISA takes advantage of decades of development by NASA from the 1970's to 1980's during the Space Station Freedom program, the precursor to the ISS. The mechanical connector was originally designed for rapid astronaut assembly while also providing a high quality structural connection with linear load deflection response. The paper will discuss the business case for ISA, the general approach taken to exploit on-orbit assembly in the GEO communication satellite market, and the concept of operations associated with the ISA approach, thus laying the foundation for ISA to become an accepted operational approach for commercial in-space operations.

\section{Disclaimer}

Thoughts and opinions outlined in this document are those of the authors and do not necessarily reflect those of the United States Government, affiliated agencies or Department of Defense (DoD).

\footnotetext{
${ }^{1}$ Chief Architect - Robotics and Automation, Non Member

${ }^{2}$ Chief Architect - New Space Ventures, Non Member

${ }^{3}$ VP US Government Solutions, Non Member

${ }^{4}$ Senior Spacecraft Configuration Engineer, Non Member

${ }^{5}$ Senior Antenna Mechanical Engineer, Non Member

${ }^{6}$ Senior Spacecraft Mechanisms Engineer, Non Member

${ }^{7}$ Senior Robotics Systems Engineer, Senior Member

${ }^{8}$ Research Engineer, Structural Mechanics and Concepts Branch, M/S 190, AIAA Associate Fellow

${ }^{9}$ Research Engineer, Structural Mechanics and Concepts Branch, M/S 190, AIAA Associate Fellow

${ }^{10}$ Senior Designer, Northrup Grumman Technical Services, M/S 238, Non Member

${ }^{11}$ Portfolio Manager, In-space Robotic Assembly, Large Structures, M/S 104, Non Member
} 


\section{Nomenclature}

$\begin{array}{ll}\text { ASEM } & \text { Assembly of Station by EVA Methods } \\ \text { ComSat } & \text { Communication Satellite } \\ \text { DOF } & \text { Degrees of Freedom } \\ \text { Gbps/ } \$ & \text { Gigabits per second per dollar } \\ \text { GEO } & \text { GEosynchronous Orbit } \\ \text { DARPA } & \text { Defense Advanced Research Projects Agency } \\ \text { DoD } & \text { Department of Defense } \\ \text { EVA } & \text { Extra-Vehicular Activity performed by astronauts } \\ \text { ISA } & \text { In-Space Assembly } \\ \text { MCC } & \text { Mission Control Center } \\ \text { NASA } & \text { National Aeronautics and Space Administration } \\ \text { PODS } & \text { Payload Orbital Delivery System } \\ \text { RF } & \text { Radio Frequency } \\ \text { SSL } & \text { Space System Loral } \\ \text { STS } & \text { Space Transportation System } \\ \text { TTO } & \text { Tactical Technology Office (within DARPA) }\end{array}$

\section{Introduction}

Current commercial satellite systems are inflexible assets whose capability is defined during early purchase negotiations and becomes fixed at launch. Launch vehicle constraints on payload launch mass and volume severely limit resulting operational performance. A new deployment paradigm is needed for space operations to separate the operational spacecraft configuration from the constraints of the launch vehicle. The new paradigm; in-space assembly (ISA), which enables routine spacecraft assembly, refurbishment, repair and upgrade, will enable cost effective emplacement of space systems that are operationally versatile. Operational performance will be enhanced through routine visits by an automated agent capable of: a) integrating new technologies as they become available, b) expanding or reconfiguring system capability to meet customer needs, c) refueling assets to extend operational life, and d) repairing or refurbishing systems in response to system degradation.

Taking the first step toward the new operational paradigm, the Tactical Technology Office (TTO) of the Defense Advanced Research Projects Agency (DARPA) recently funded a study led by Space Systems Loral (SSL), called Dragonfly, to evaluate the feasibility of assembling antenna farms on orbit during the commissioning phase of a standard communications satellite in geosynchronous orbit (GEO). The premise of the study was that ISA enabled alternative packaging and deployment approaches for larger reflectors, as well as the opportunity to carry additional reflectors, thus doubling the operational capability of a conventional GEO communication satellite (ComSat) by better exploiting the available launch fairing volume. This inaugural application of in-space assembly provides an obvious economic benefit to GEO ComSat customers while simultaneously blazing the path for applying ISA to other volume constrained sub-systems such as solar arrays and thermal radiating surfaces.

The Dragonfly project uses an ultra-light-weight robot, leveraging Mars rover and Mars Phoenix Lander robotic technologies, which performs the in-space antenna assembly using a specialized tool derived from experience within the DARPA Orbital Express Autonomous Satellite Servicing Mission and National Aeronautic and Space Administration (NASA) Automated Structure Assembly Laboratory. ${ }^{1,2}$ The process of assembling a precise and thermally stable mechanical connection is coordinated using the approach proven through a decade of space station assembly. ${ }^{3,4,5}$ The mechanical connector chosen leverages a mature flight proven design developed by NASA as an approach to ISA by astronauts. The paper will discuss the overall concept of operations, the business case for ISA, the history of the mechanical connection and the general approach taken to exploit on-orbit assembly in the GEO ComSat market, thus laying the foundation for ISA to become an accepted operational approach for commercial inspace operations. 


\section{Commercial Business Case - ISA of Radio Frequency (RF) Apertures is low hanging fruit}

One of the most fundamental physical factors limiting satellite data capacity is aperture area, defined by the diameter of the primary reflector of an antenna: more aperture is better. However, reflector area is constrained by launch vehicle fairing volume and the ability to package solid reflector dishes around the satellite bus. Unfurlable mesh reflectors can overcome the fairing volume constraint but are limited by the cost, mass, complexity and reliability of deployment mechanisms. Further, at desired high frequency bands such as Ka and above, only a solid reflector or very expensive multi-layered mesh reflector can provide the required surface accuracy and reflectivity to achieve desired performance. In order to demonstrate the feasibility of disruptively overcoming this fairing constraint, the Dragonfly project performed a ground demonstration of a prototype robotic ISA capability that retires the major technical hurdles for flight and provides a practical way to increase the size and number of solid reflectors on each satellite.

Using existing low risk space robotics technologies to overcome fairing volume constraints and increase satellite mission capability will dramatically improve satellite performance and overall mission value for the same capital investment as today. The near term goal is to substantially increase transmitted data rate, Gigabits per second per dollar (Gbps/\$), by doubling the data rate of the current state of the art satellite, just by increasing aperture area. For a commercial customer, this doubling of the data rate doubles the rate of return on the sizable capital investment for a GEO ComSat or provides the opportunity to reduce service fees to compete with terrestrial service providers and expand in all markets. In combination with current digital RF payload improvements such as beam hopping, power balancing and beam forming, this factor of 2 improvement increases dramatically as the communication links are dynamically tuned instantaneously to meet the market demand, profoundly impacting the operating budget of customers. The improved ComSat performance benefits operators, consumers and the US government customers by: enabling a lower cost service, the use of small hand held terminals for persistent communications on the move and by providing a tighter beam with increased data rate to high density and congested areas. Table 1 summarizes the new mission opportunities resulting from using a robot to assemble larger reflector area or by creating a system capable of exchanging reflectors.

Table 1. Assembled antennas offer many architectural choices and business transition opportunities

\begin{tabular}{|l|l|}
\hline \multicolumn{1}{|c|}{ Selected Architecture } & \multicolumn{1}{|c|}{ Technical Transition Applications and Benefits } \\
\hline Larger reflectors & $\begin{array}{l}\text { - Higher throughput data rate for broadband and comm-on-the-move } \\
\text { - Increased transmitted data/\$ for reduced cost of service } \\
\text { - Extensive frequency reuse for more data per allocated spectrum } \\
\text { - Narrower beam possible for directed comm } \\
\text { - Better beam isolation, roll-off for improved comm security and capacity }\end{array}$ \\
\hline Additional reflectors & $\begin{array}{l}\text { - Additional, more, diverse coverage per satellite } \\
\text { - Additional throughput via more transponders } \\
\text { - Wider geographic coverage, more selective spot coverage to match traffic }\end{array}$ \\
\hline Exchangeable reflectors & $\begin{array}{l}\text { - Replace or reposition reflectors on-orbit to support a variety of coverage patterns } \\
\text { for different and reconfigurable missions throughout satellite life }\end{array}$ \\
& $\begin{array}{l}\text { - Ability to launch and install new/alternate reflectors over the mission (via a service } \\
\text { like SSL's GEO- Payload Orbital Delivery System (PODS)) to expand the mission } \\
\text { and performance }\end{array}$ \\
\hline
\end{tabular}

The extended satellite capabilities and benefits outlined in Table 1 are a compilation of GEO satellite operator desires that have been articulated in commercial solicitations over the past year. In-space assembly promises to provide a near term solution to these ambitious desires and paves the way to more ambitious in-space manufacturing and assembly solutions.

\section{Concept of Operations}

The Dragonfly project developed and performed mock-up tests of an ISA concept that demonstrates a 2 times improvement in performance relative to a design reference mission which uses an inexpensive shared launch spacecraft located in a lower Ariane position. This challenging launch arrangement is relatively inexpensive, but by virtue of its restricted geometry, highly constrains the spacecraft volume. This limits the total aperture area which consequently limits potential RF throughput, and thus revenue. By using ISA, it is possible to change this economic equation by adding two reflectors to the current state of the art of four reflectors, and increasing the reflector size by 
at least $15 \%$ (which is well within geometric constraints of the novel reflector stowage method for launch). This additional aperture area increases the data throughput of this small satellite to that of a standard full-sized ComSat, which directly results in a 2 times increase in the value of the spacecraft to customers. Because the spacecraft can be marketed as a full sized ComSat capability at the lower cost of the smaller dual launch ComSat, new customers who can only afford the smaller ComSat, in a lower Ariane launch, can enter the market at reduced capital expense.

Figure 1 shows a proposed flight demonstration for in-space robotic antenna assembly as applied to a small, lower position shared launch satellite. Larger views of the assembled and packaged spacecraft are shown in Fig. 2 where the robot used for assembly is highlighted. The key elements of the Concept of Operations are as follows:

- The satellite will retain all of its standard subsystems including standard reflector designs, but the reflectors will be larger than what is possible today and additional reflectors are included on each launch. As shown in Figs. $1 \mathrm{a}$ and $2 \mathrm{~b}$, the larger one-piece solid reflectors will be launched in a stack on the Earth deck to take advantage of the full fairing diameter and reduced launch loading. Future flights will include even larger reflectors that are launched in pieces and assembled in-space. Assembly occurs as follows: first the reflector is removed from the earth deck (Fig. 1a) and translated (Fig. 1b) to the installation position where the reflector

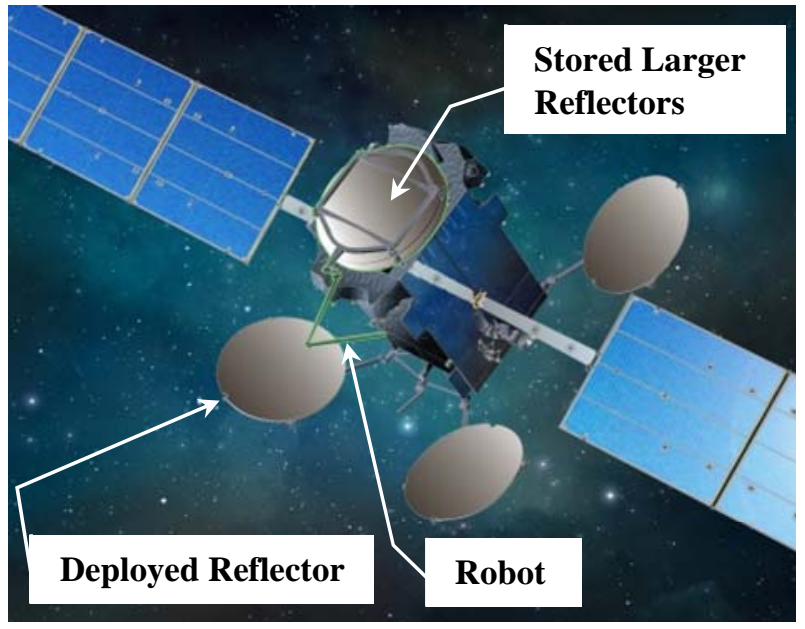

a) First robotically installed reflector removed from storage location after 4 reflectors deployed conventionally.

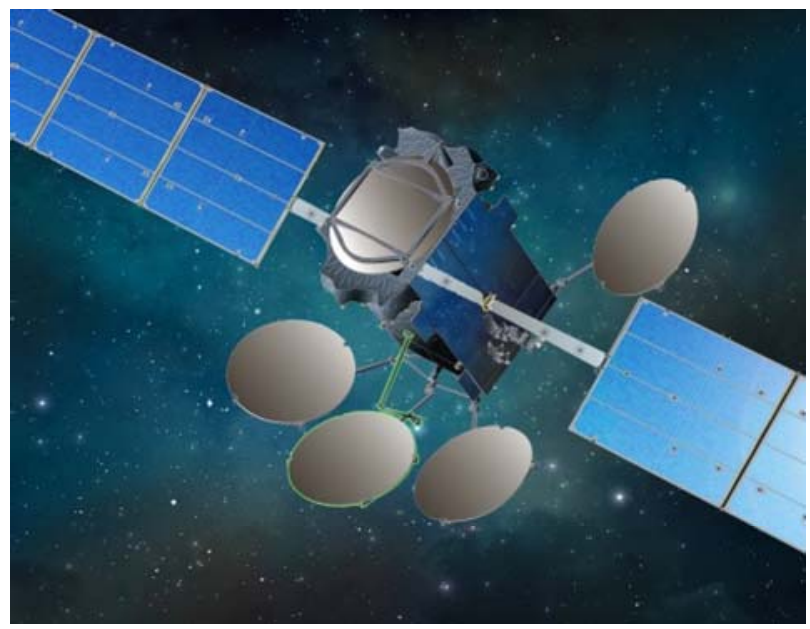

c) First robotically installed reflector secured to operational location.

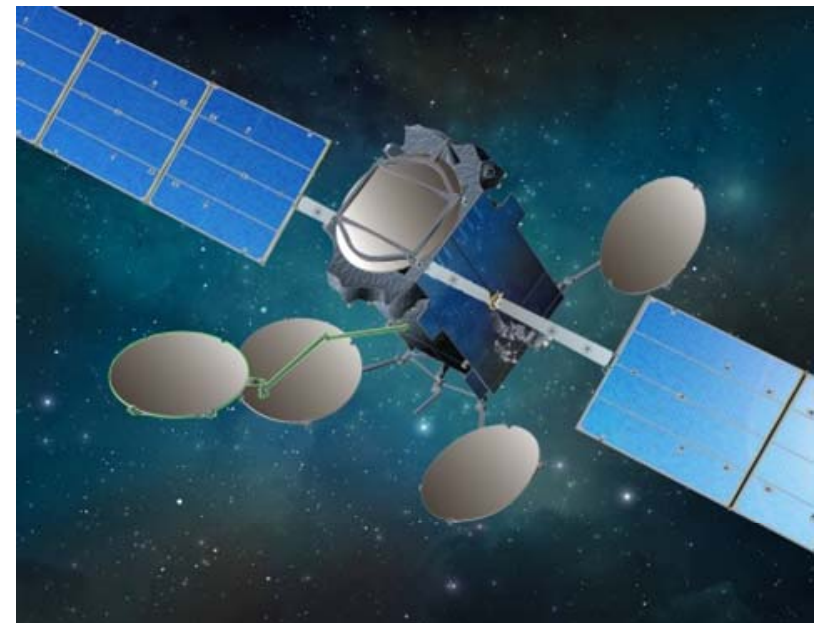

b) First robotically installed reflector translated to installation location.

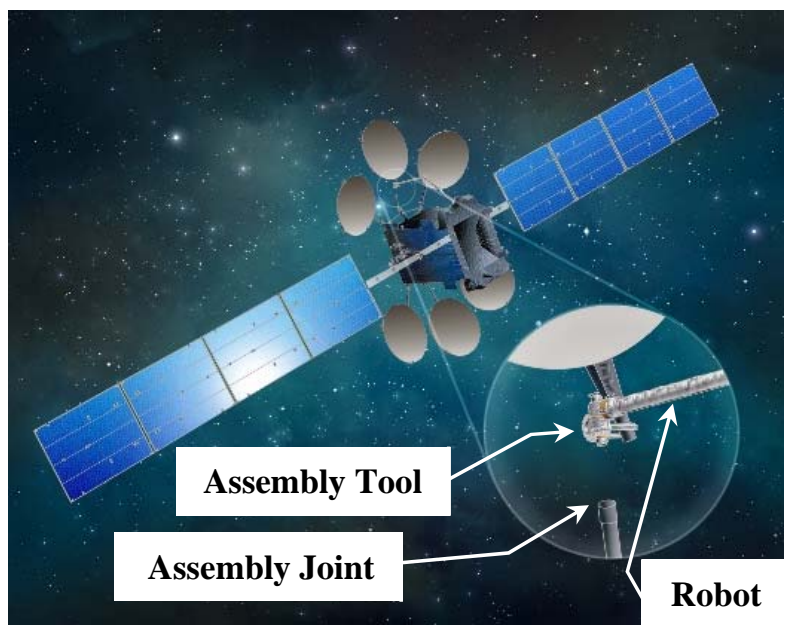

d) Second robotically installed reflector secured to operational location.

Figure 1. An ultra-light robotic arm installs two additional solid reflectors in a near term flight demonstration on an operational commercial GEO ComSat. 
is secured (Fig. 1c) followed by a similar sequence to install the second reflector (Fig. 1d). It is straightforward to extend the assembly to add additional reflectors, relocating the robot as needed.

- Each satellite will carry its own ultra-light assembly robot (stowed for launch alongside the reflectors on the Earth deck in Fig. 2b) that will perform the initial assembly during the satellite commissioning phase, and any reconfigurations that may occur throughout the life of the mission. The robot will share the existing spacecraft processor and internal data bus to minimize integration cost and changes to the standard spacecraft. Once ISA becomes a common approach, a resident GEO servicer will perform the assembly rather than each satellite supporting its own robotic equipment.

- The robot is commanded from the standard GEO ComSat Mission Control Center (MCC) using a custom command and control console tied to a virtual payload channel via the standard commanding uplink (2 kbps) and telemetry downlink (16 kbps $\mathrm{x} 3$ channels). This additional function has virtually no impact on the MCC and its operating protocol.

- The robot is controlled through a combination of pre-programmed scripts and an in-situ registration process to match trajectories to the actual geometric environment. A set of visual situational awareness cameras provides compressed imagery to ground based operators who monitor progress and provide simple, asynchronous commands such as "trigger next sequence”, "bump two steps left, then continue script”, and "re-register now". A bore sight camera provides imagery for proximity and contact alignment as well as verification of tool operation.

- Registration of the robot and tool on the spacecraft can be performed at any time through an operator command that downlinks a hi-resolution image from any camera to a vision-based pose estimator running on the ground. This utility automatically uploads a command that adjusts the robot tool position and orientation to match the pre-planned/scripted pose relative to any selected feature, such as a fiducial mark or target. The re-registered script continues from where it was interrupted for registration.

- Local force control in the robot handles any remaining misalignments during contact operations such as grasping and insertion/withdrawal tasks during assembly and disassembly to achieve strain free assembly.

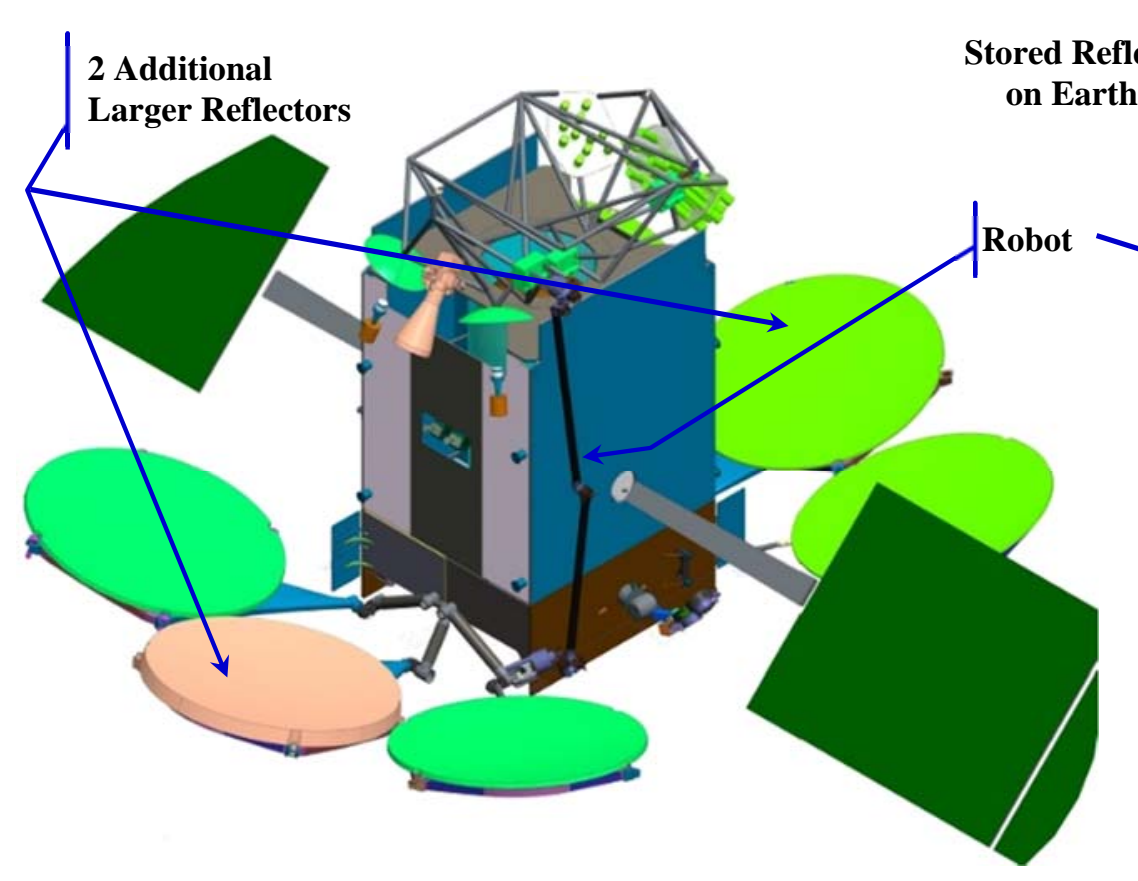

a) Deployed Spacecraft

Figure 2. ISA enables packaging of 2 additional larger reflectors. 


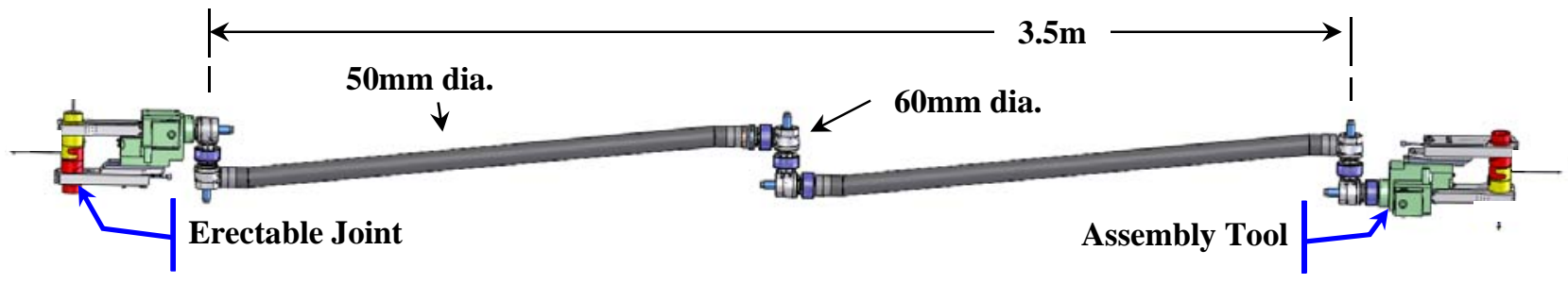

Figure 3. Assembly robot and tool.

This concept of operations and robotic control method is a unique combination of the techniques proven in over 10 years of ground controlled robotic operations on the International Space Station and the autonomy elements flown in the DARPA Orbital Express satellite servicing demonstration mission.

The assembly robot is designed to be very light-weight, inexpensive and nearly symmetric as shown in Fig. 3 . The robot is $3.5 \mathrm{~m}$ long and has 7 degrees of freedom (DOF) and reuses the actuators from the Mars Exploration Rover robotic arm. It has two identical assembly tools (one on each end) that allow the robot to step end over end from base point to base point to reach and access antenna assembly points around the anti-Earth deck of a large GEO ComSat. Important trades to conduct as the concept matures are to: 1) determine the minimum DOF's required in the robot for assembly and, 2) determine the minimum robot precision requirements. For the robot shown in Fig. 3, two rotary axes have been moved from the ends to the central elbow to reduce inertia and help maintain a slender wrist/base at the ends. In this ISA concept, the robot replaces the majority of the traditional antenna deployment systems which are normally large multi-degree of freedom devices attached to each reflector and sized to support the reflectors during

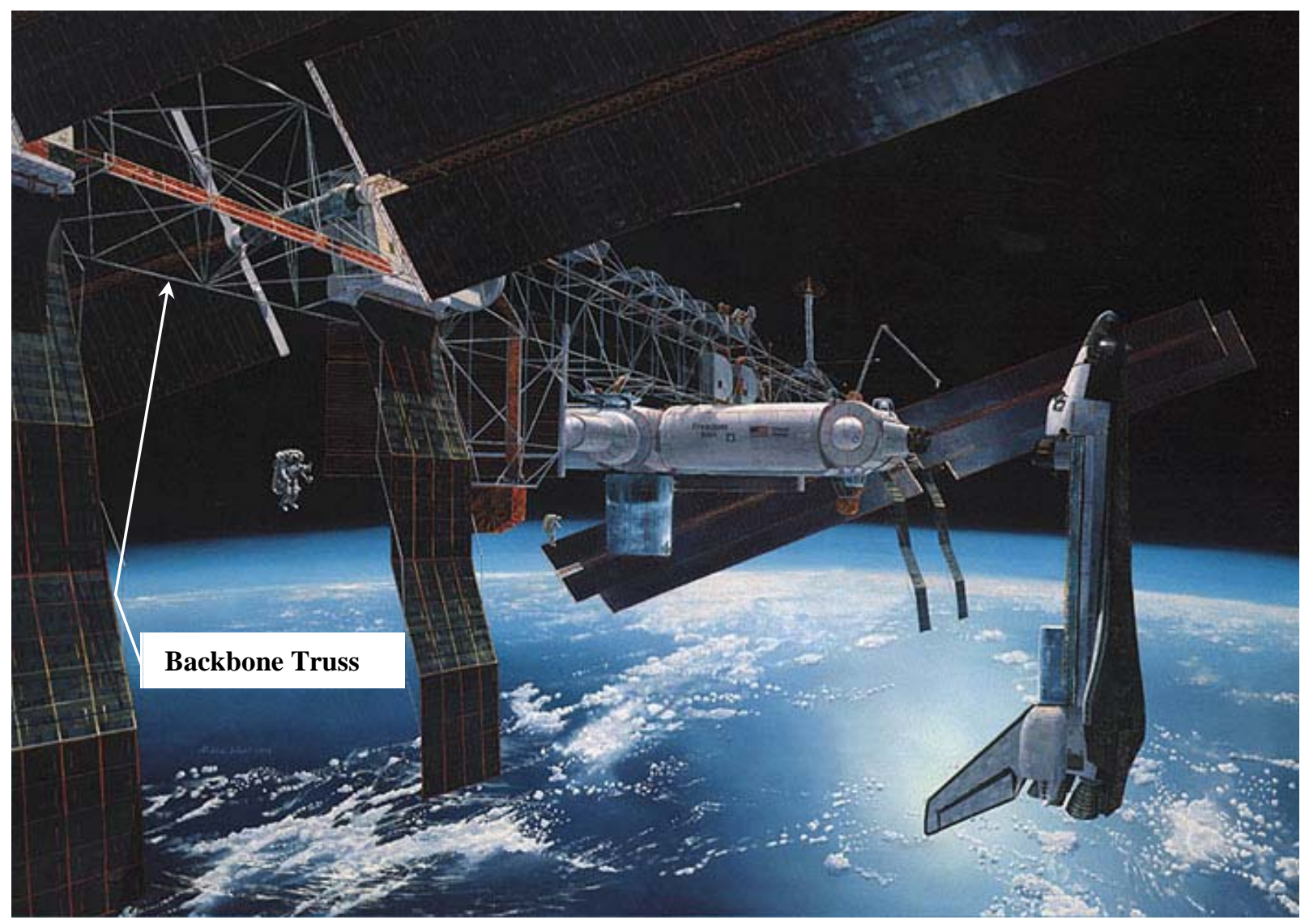

Figure 4. Space Station Freedom concept. 
launch. This replacement enables an overall reduction in system complexity and mass, in addition to an increase in performance afforded by the increase in reflector size.

\section{In-Space Assembly History}

In the 1980's and 1990's considerable effort at NASA was directed at developing ISA techniques including several NASA flight experiments including Space Transportation System (STS) 37, 49 and 61B. ${ }^{6}$ A primary focus of that work was to investigate efficient assembly of a space station, in particular the Space Station Freedom shown in Fig. 4. ${ }^{7,8,9,10}$ One promising construction method extensively developed was referred to as erectable assembly. Erectable truss structures, which can be assembled component-by-component on orbit, package very efficiently for launch. ${ }^{11,12}$ Once on orbit, the pieces would be assembled to form the truss structure by an astronaut extra vehicular activity (EVA) using efficient assembly line-type techniques and translation aids, such as the mobile transporter, that were used to locate the astronauts for assembly as shown during neutral buoyancy tests in Fig. 5. ${ }^{13,14,15}$ Extensive studies were performed that addressed the truss structure design, launch payload packaging concepts, structural analysis, assembly concepts, structural tests and assembly tests. ${ }^{16}$ A side insertion assembly joint with linear load deflection response was developed for efficient astronaut assembly of the 5-m cross section square bay backbone truss identified in Fig. 4 and shown during a neutral buoyancy assembly test in Fig. 5. 17,18,19 Key features of the joint, shown in Fig. 6, included: 1) a spring-loaded internal latch which facilitated initial capture and secured the joint, 2) a hand-operated collar which was rotated to lock and preload the joint, and 3) linear axial structural performance. The space suits worn

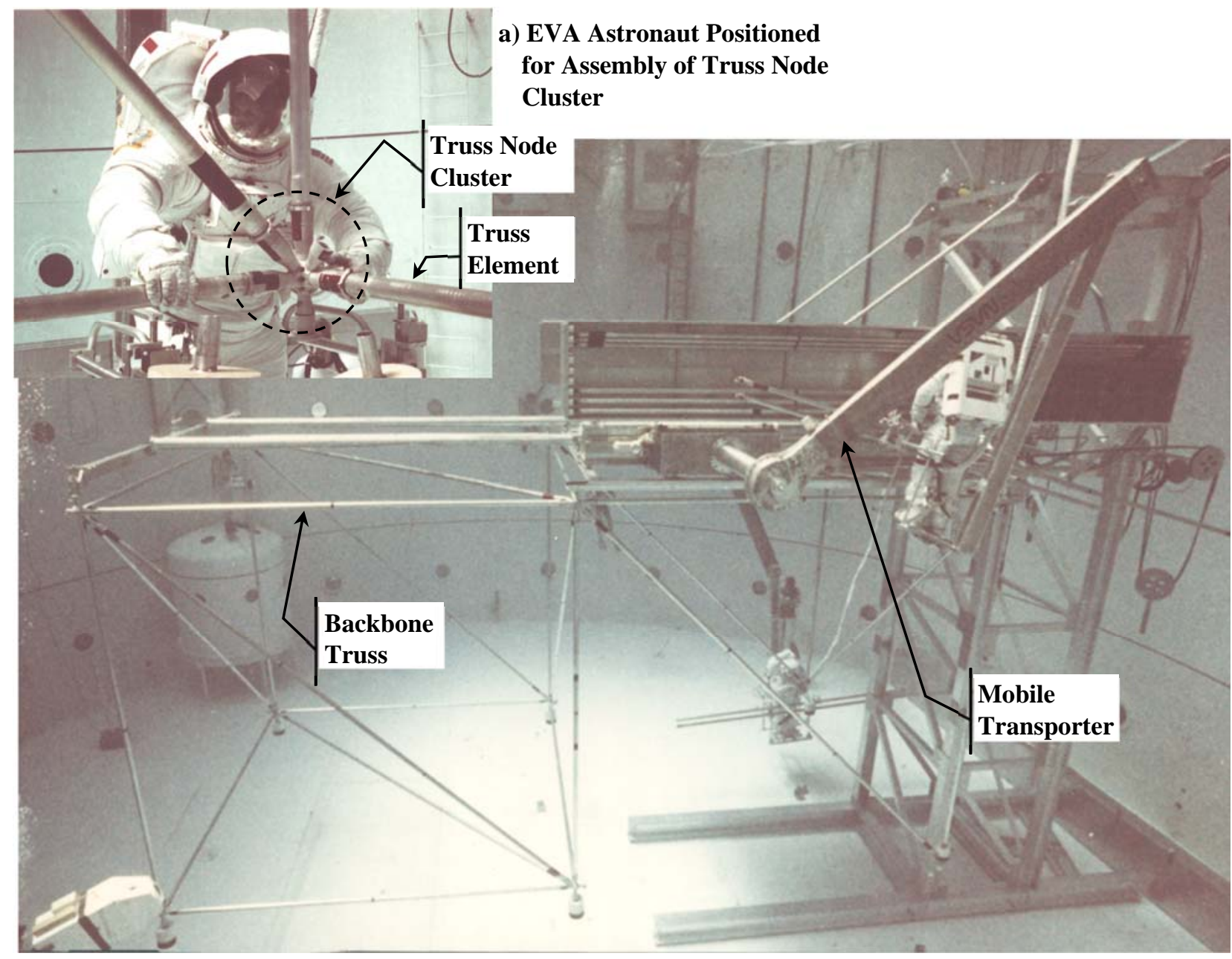

b) Neutral Buoyancy Backbone Truss Assembly Tests

Figure 5. Mobile transporter for EVA positioning. 


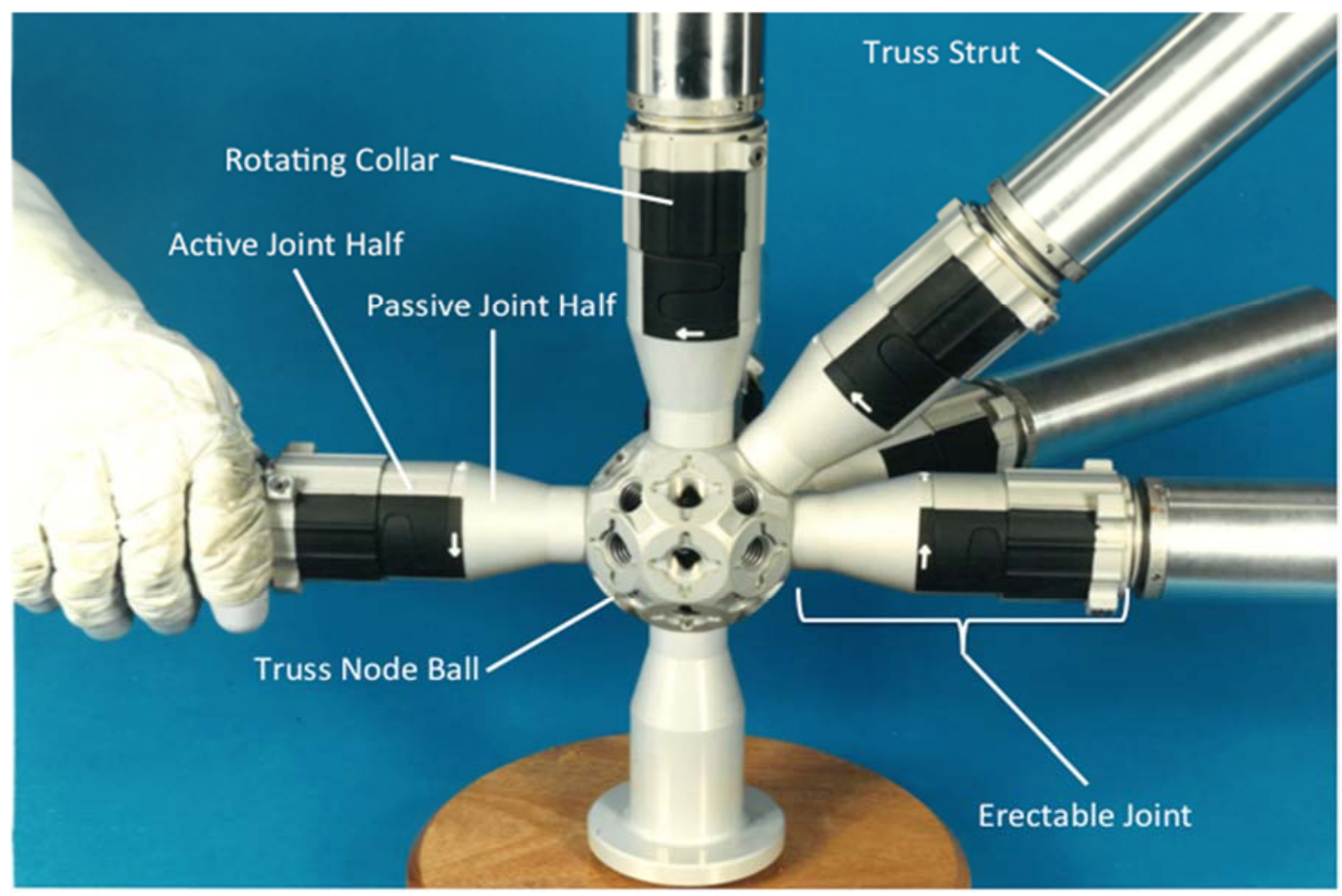

Figure 6. LaRC 2-inch erectable node cluster consisting of erectable joints attached to a central node.

by EVA astronauts are bulky and the internal pressure causes the suits to be stiff. The stiffness induced in the spacesuit gloves limits the dexterity of the astronaut's hand operations and also requires the astronaut to exert force to open or close the glove from its neutral position. The erectable joint design and the 2-inch size were optimized to minimize astronaut hand fatigue. ${ }^{20}$ In 1992, on Space Shuttle flight STS 49, the LaRC 2-inch erectable joints were flown as part

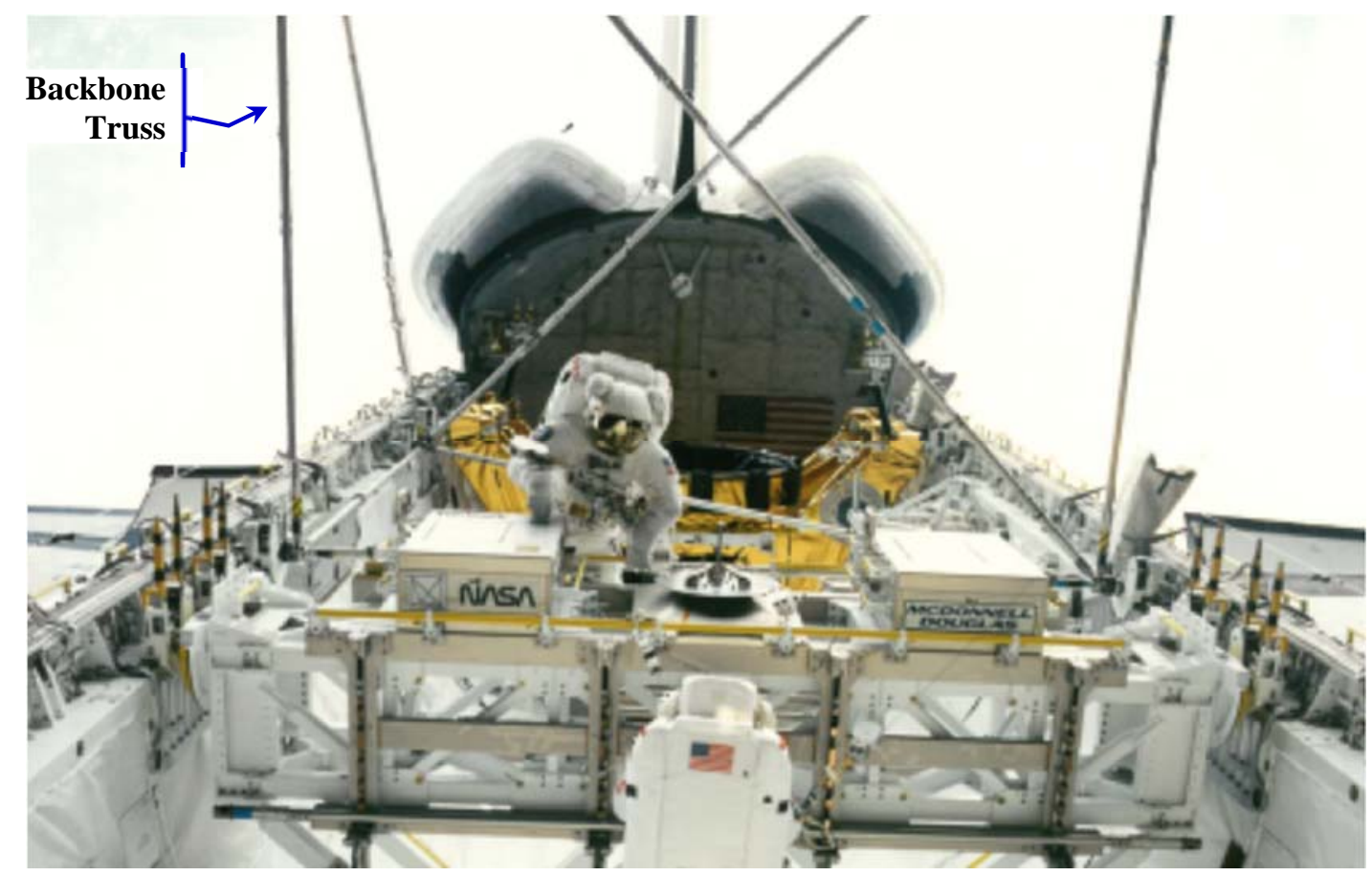

Figure 7. ASEM flight experiment, STS 49.

American Institute of Aeronautics and Astronautics 


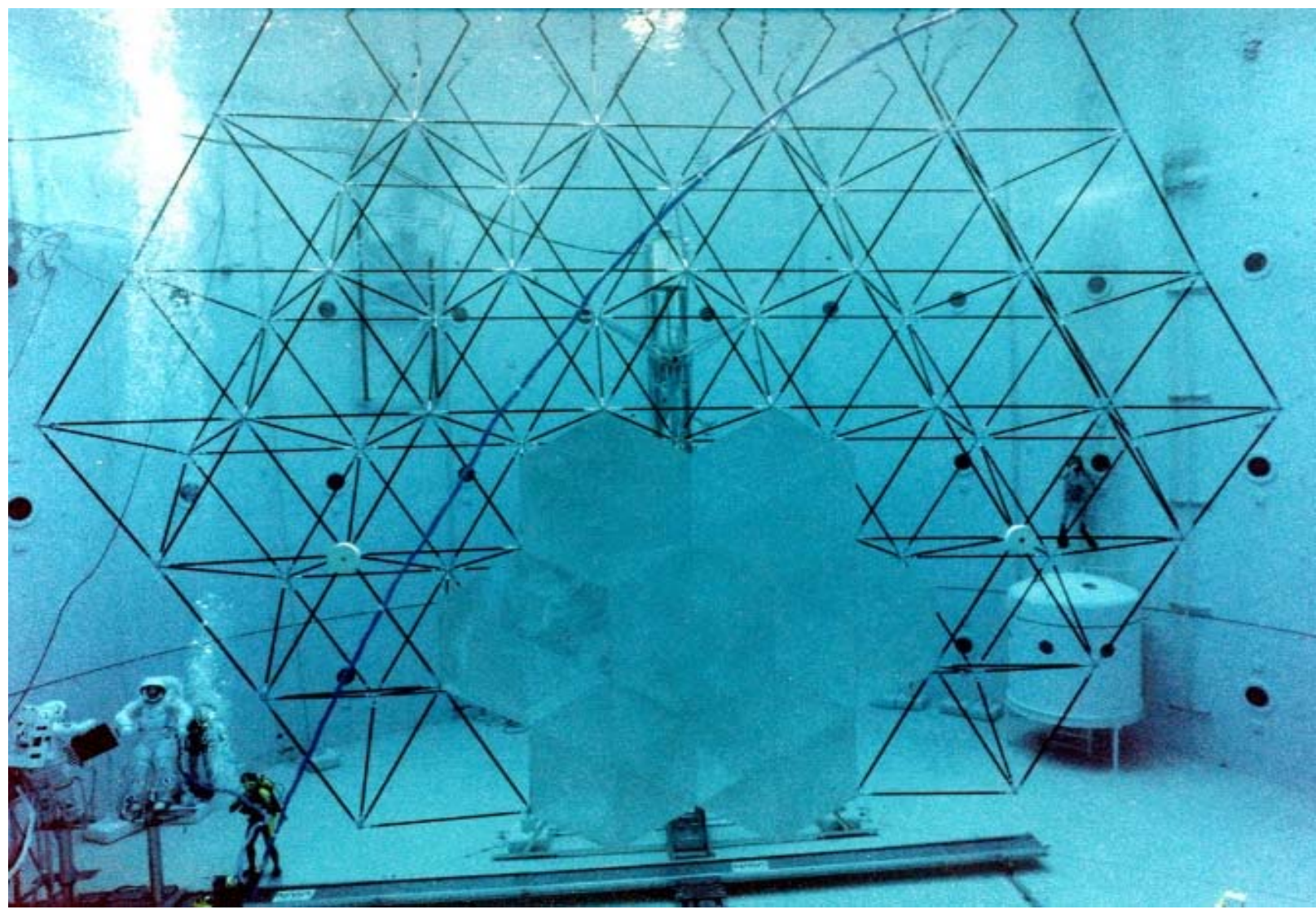

Figure 8. 14m radiometer support structure with 7 panels installed.

of the Assembly of Station by EVA Methods (ASEM) experiment, as shown in Fig. 7 where a portion of the 5-meter erectable truss was assembled in the cargo bay of the Space Shuttle on orbit. Later, the joint was scaled to approximately 1 -inch for use in the assembly of a $14 \mathrm{~m}$ radiometer primary support structure shown in Fig. $8 .^{21,22}$ In addition, to study the precision capabilities of assembled structures a small first generation structure, approximately $4 \mathrm{~m}$ in diameter, was assembled from components like those used to assemble the $14 \mathrm{~m}$ radiometer support structure. The size was selected to enable reasonable precision measurements to be made. No post assembly adjustments were made and the structure deviated from the desired shape over a range of 0.00148 to $0.00283 \mathrm{in}^{23}$ When the NASA research in large erectable space structures ended in the early 1990's, a significant amount of structural testing had been performed on the LaRC 2-inch erectable joint that was never published. Recently, there has been renewed interest in on-orbit assembly, the erectable joint technology, and the structural performance of the joints. As a result, the past work has been compiled and published. ${ }^{24}$ A summary of available test results for axial stiffness, axial strength, bending stiffness, bending strength, torsional stiffness, and torsional strength are contained in Table 2.

During the late 1990's a robotic assembly system was developed in parallel with the astronaut assembly efforts. ${ }^{2,25}$ The system used a commercially available Merlin robot to position special purpose tools in proximity of the structural assembly location, where the tools performed the operations necessary to complete the assembly step. ${ }^{26}$ In this way, the assembly is independent of the robot
Table 2. Summary of results from 2-inch erectable heritage joint tests.

\begin{tabular}{|l|l|}
\hline Joint Parameter & Heritage Data Summary Value \\
\hline Axial Stiffness & $8.88 \times 10^{5} \mathrm{lbf} /$ in (Average of 5 tests) \\
\hline Axial Strength & $20,267 \mathrm{lbf}$ (Average of 3 tests) \\
\hline Bending Stiffness (Major Axis) & $2.32 \times 10^{6} \mathrm{lb}-\mathrm{in}^{2}$ (Average of 4 tests) \\
\hline Bending Stiffness (Minor Axis) & $1.92 \times 10^{6} \mathrm{lb}-\mathrm{in}^{2}$ (Average of 4 tests) \\
\hline Bending Strength (Major Axis) & $1244 \mathrm{ft}-\mathrm{lb}(14,928$ in-lb) \\
\hline Bending Strength (Minor Axis) & $1360 \mathrm{ft}-\mathrm{lb}(16,320 \mathrm{in}-\mathrm{lb})$ \\
\hline Torsional Stiffness & $0.6198 \times 10^{6} \mathrm{lb}-\mathrm{in}^{2}$ \\
\hline Torsional Strength & $> \pm 1200 \mathrm{in}-\mathrm{lb}$ \\
\hline
\end{tabular}




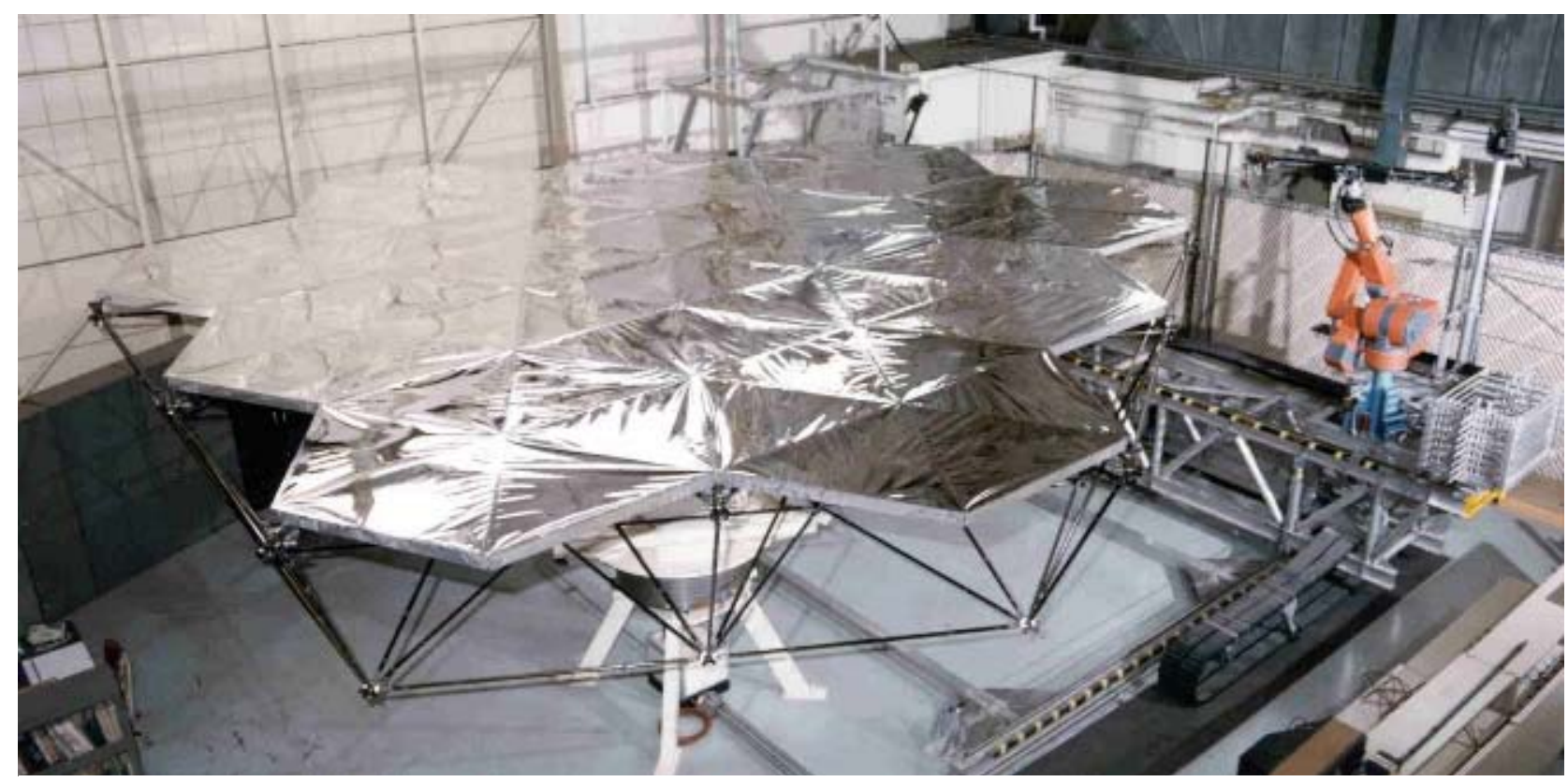

a) Autonomously Assembled Structure Consisting of 102 Truss Elements and 12 Panels

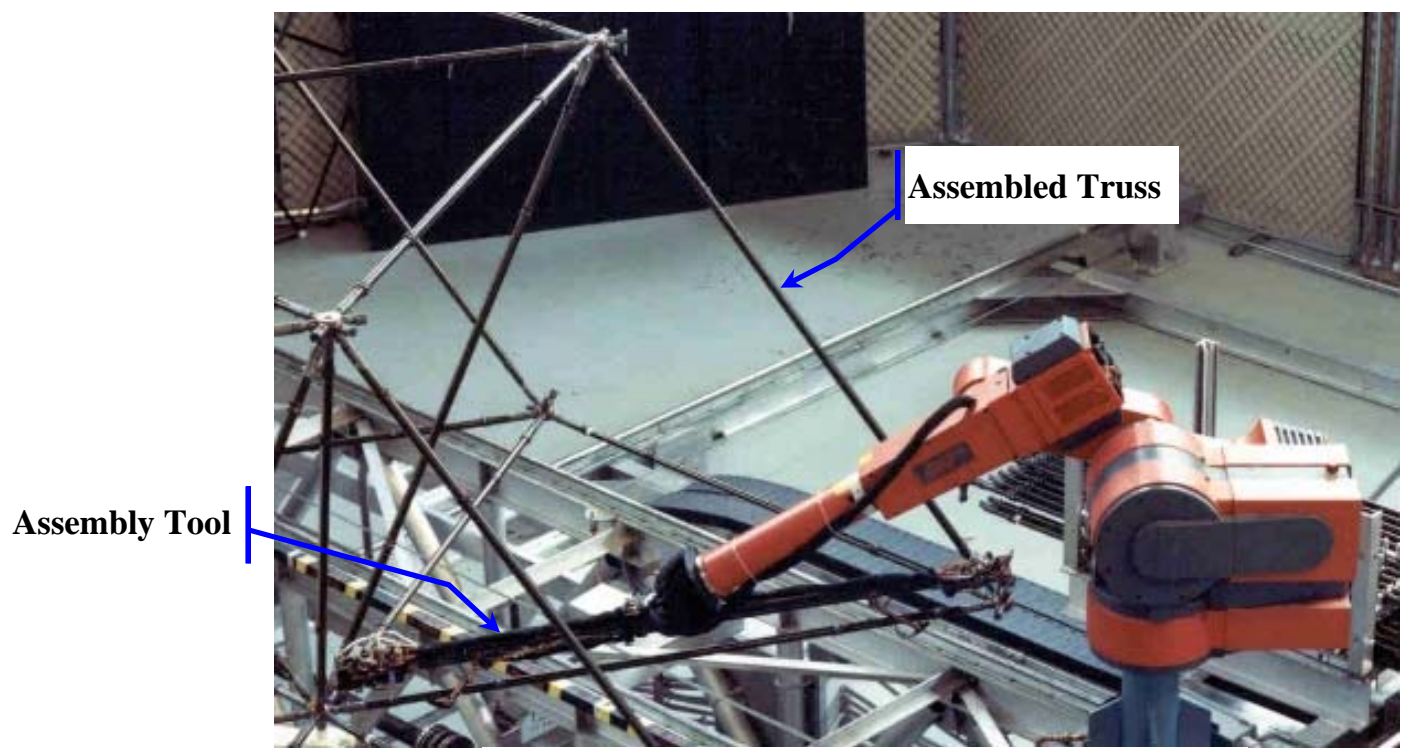

b) Robot and tool for Truss Element Assembly

Figure 9. Robotic assembly of an $8 \mathrm{~m}$ planar structure.

since the tool performs the operations necessary during assembly, any robot (or combination of robots) which can place the tool in the capture envelope of the tool at the assembly location is sufficient. Using this approach, an 8meter diameter, planar structure composed of 102 truss elements and covered with 12 reflector panels was repeatedly, autonomously assembled and disassembled (Fig. 9a) using custom tools (Fig. 9b).

\section{Robotically Compatible Erectable Joint}

To create a robotically compatible structural joint, the joint shown in Fig. 6 was redesigned to enable efficient robotic assembly. The EVA joint shown in Fig. 6 was originally designed for assembly of a relatively small number of connections without tools. This meant that each joint included the equivalent of a tool to ease EVA assembly, which increased the complexity and mass of the joint. The first step in redesigning the heritage EVA joint for robotic 


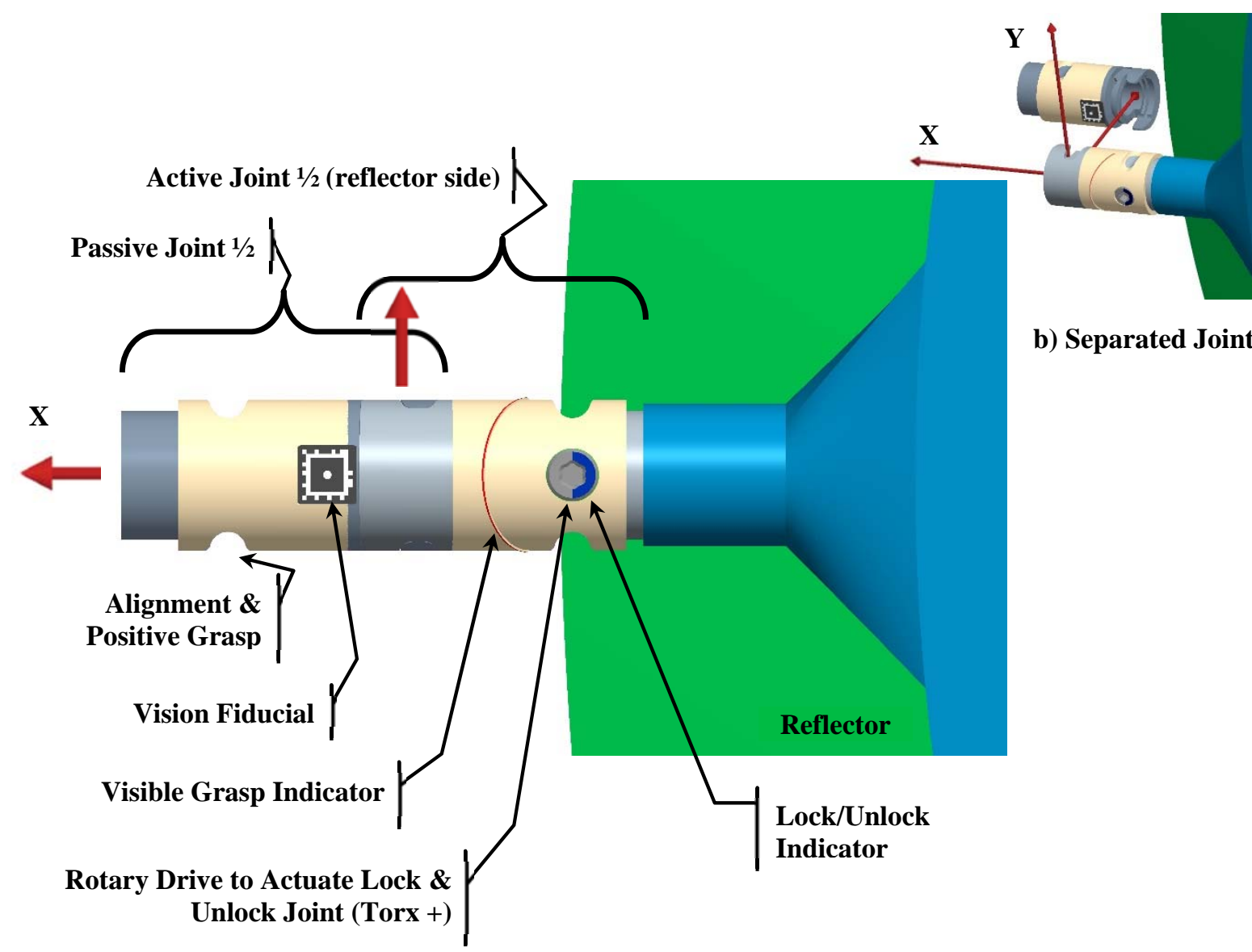

a) Robotically Compatible Joint Features

Figure 10. Robotically compatible joint attached to reflector.

assembly was eliminating these EVA specific features while creating an efficient interface to a robotic tool. The tool's primary function is to achieve reliable and robust joint assembly or disassembly, while the joint is optimized for efficient structural performance, which minimizes the impact of the mechanical connection on the overall performance of the assembled structure.

The design objectives for the robotically compatible erectable joint were to:

1) Enable reliable assembly and disassembly of the joint using a rotary drive,

2) Correct for misalignments in robot positioning,

3) Provide visual feedback to an operator that is sufficient to assess assembly success,

4) Minimize the complexity of the joint and tool system, and

5) Minimize the mass of the joint system.

The joint of Fig. 6 was redesigned to meet these objectives, while maintaining the contact surfaces which provided the linear load deflection response resulting in the robotically compatible joint shown in Fig. 10. The joint is composed of two joint halves, an active and passive joint half, which are shown separated in Fig. 10b. The active side contains the mechanical components that move to lock and secure the joint. The robotically compatible joint contains alignment features, operator visual aids (such as the "vision grasp indicator"), a vision fiducial, and a Torx+® driver interface as indicated in the figure. The tool used to assemble or disassemble the joint is shown conceptually in Fig. 11. The tool uses 2 sets of grippers to react forces locally, thus making assembly and disassembly independent of the robot capabilities. The tool design allows nearly a $+/-1 \mathrm{~cm}$ positioning error in all axes, reducing the precision requirements of the positioning robot. 


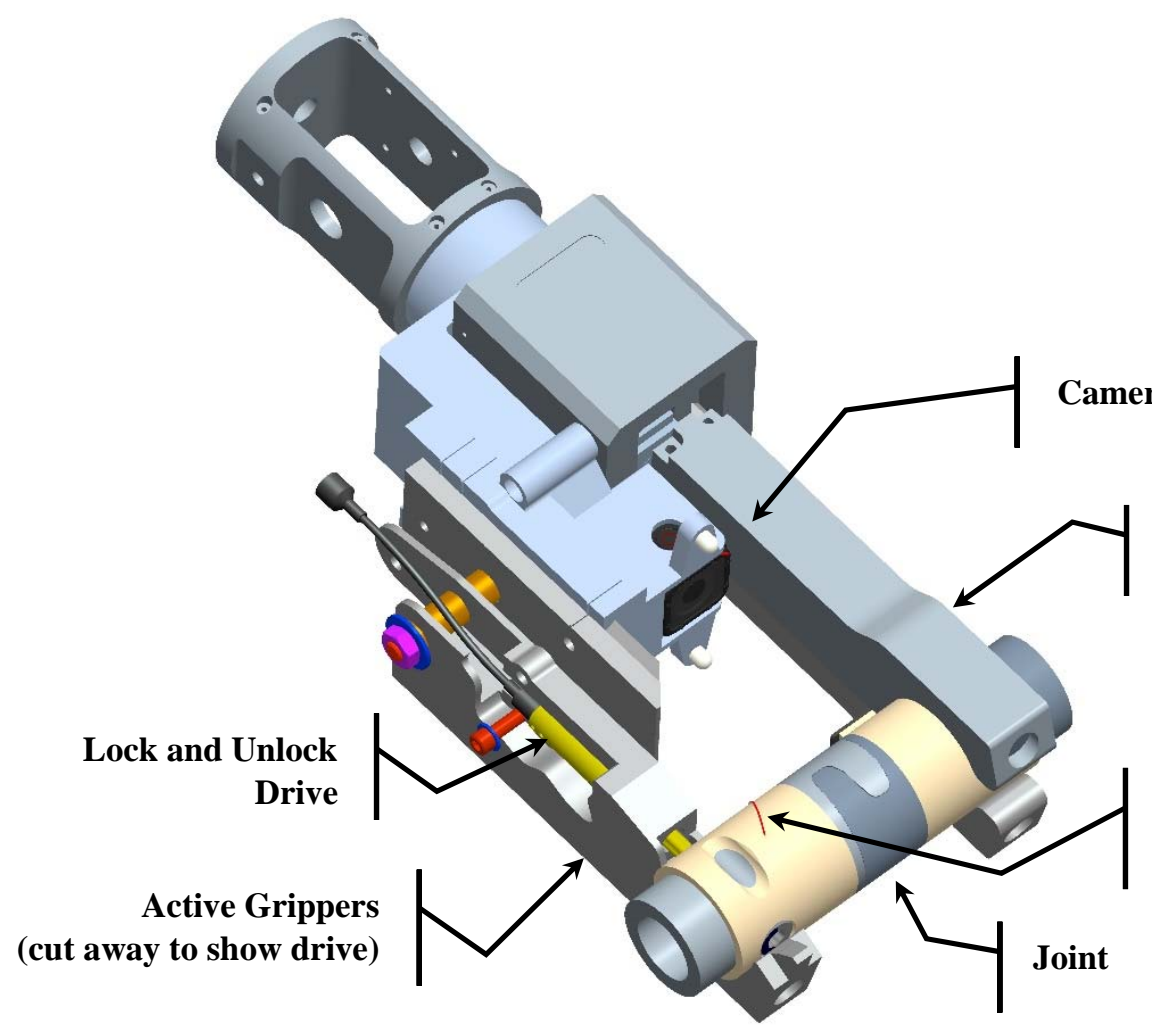

a) Conceptual Tool Grasping the Joint
Passive Grippers

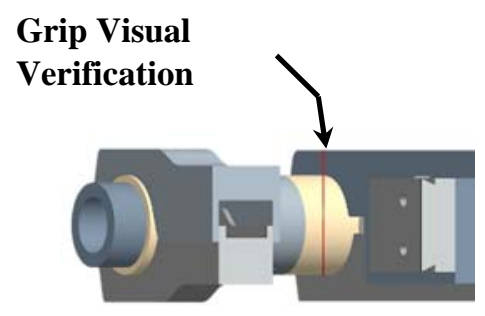

b) Operator View of Visual Grip Indicator

Figure 11. Conceptual assembly and disassembly tool operating on joint.

\section{Assembly Experiment Summary}

In order to validate the feasibility and maturity of the proposed assembly approach, existing heritage joint components were modified and the assembly sequence was executed in a room temperature laboratory environment. A high fidelity reflector was attached to the modified joints and an available Schunk gripper was adapted and integrated with an available robot to enable positioning of a semi-manual tool, similar to that shown in Fig. 11, in a mockup test to demonstrate the feasibility of the proposed approach. The mockup is shown in Fig. 12 with representative graphics in Fig. 12a and in the laboratory test setup shown in Fig. 12b. In Fig. 12b the reflector is visible in the lower right, starting in the storage location, corresponding to the earth deck of Fig. 2. In Fig. 12b the robot has positioned the assembly tool in the approach position in preparation for grasping the joint. The installation location for the reflector is identified on the left side of Fig. 12b and corresponds to a location on the anti-Earth deck of the satellite as shown in Fig. 12a. Table 3 lists representative steps for an installing a reflector and shows two views from proposed camera systems at each step. The operator view is provided by a bore sight camera (Fig. 11) aligned with the fiducial when the joint is grasped, enabling automatic vision-based robotic alignment as well as operator monitoring of the joint grasp and actuation. The second camera provides a global view of the assembly operation and is used to verify the robot is moving as expected and appropriate clearance is maintained between the reflector being installed and the other spacecraft components. Reflector installation starts with approach (Fig. 12, and Table 3 step 1), grasp and removal of the reflector from the storage location on the earth deck (steps 2-4). The reflector is removed by separating the joint at the storage location using the tool shown in Fig. 11. The robot then translates the reflector to the installation location (step 5) and uses the tool to secure the joint at the installation position (steps 6 and 7) followed by releasing the joint and withdrawing (step 8) at which point the process can be repeated to install another reflector. The successful test confirm the feasibility of the proposed approach as well as the ability to make the connection without exerting 
large forces into either the assembled structure or the positioning robot. The tests also highlight the importance of having adequate camera coverage and lessons learned from the tests will be used to improve the design of next generation hardware.

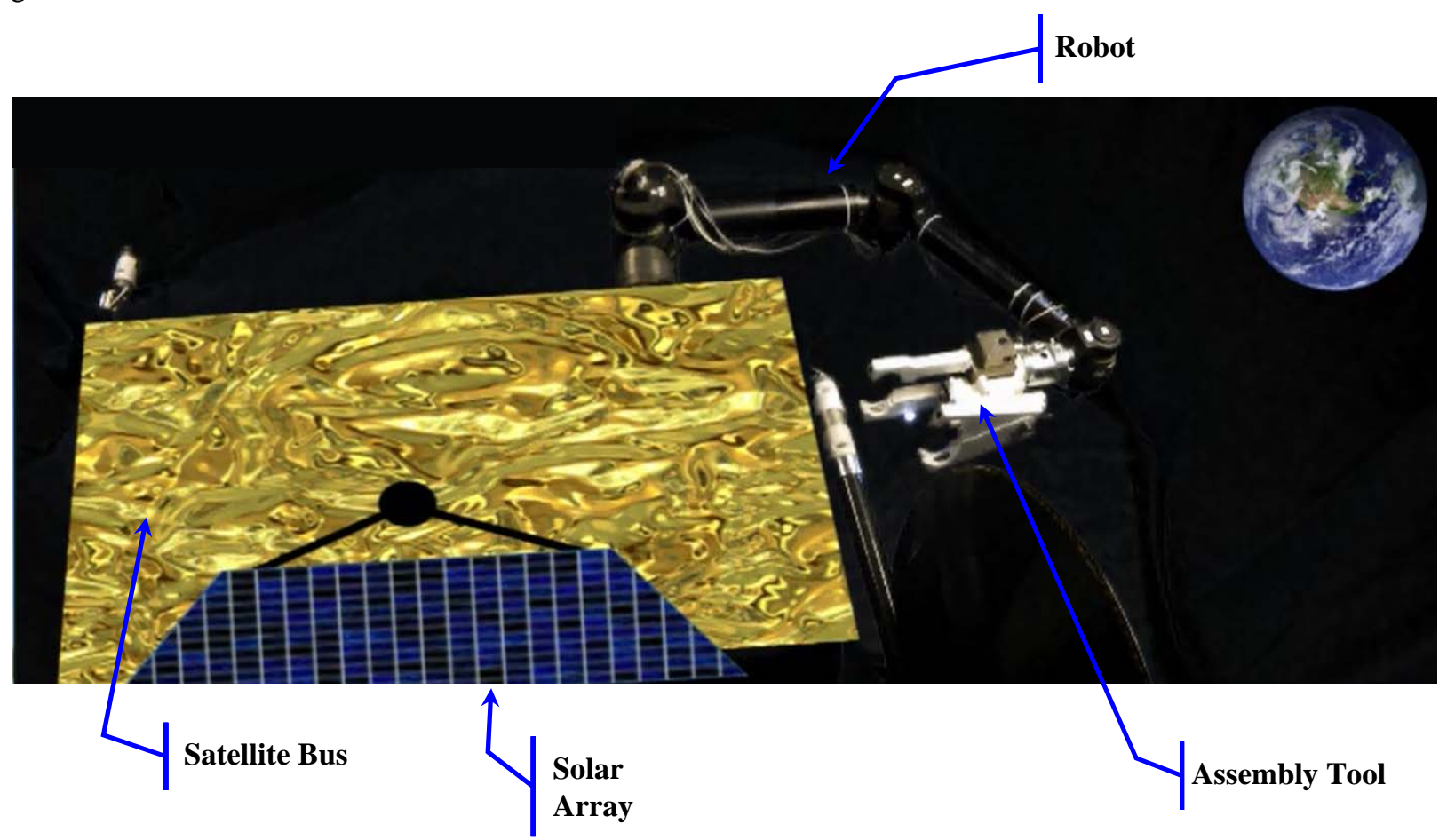

a) Mock-Up with Representative Graphics for Satellite Added

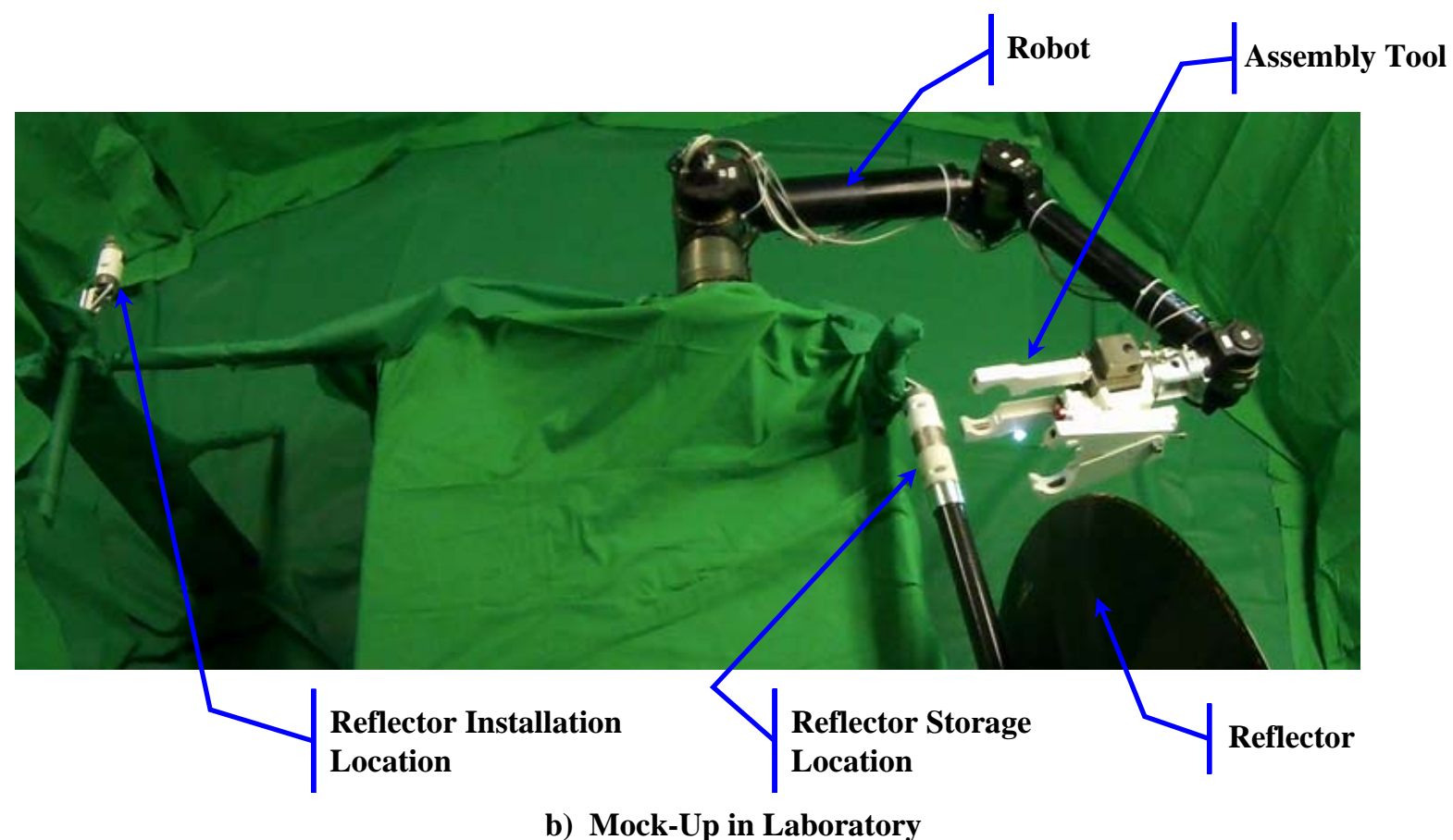

Figure 12. Mock-up to test satellite reflector assembly feasibility showing robotic tool positioned at storage canister approach location. 
Table 3. Steps for installing a reflector on orbit.

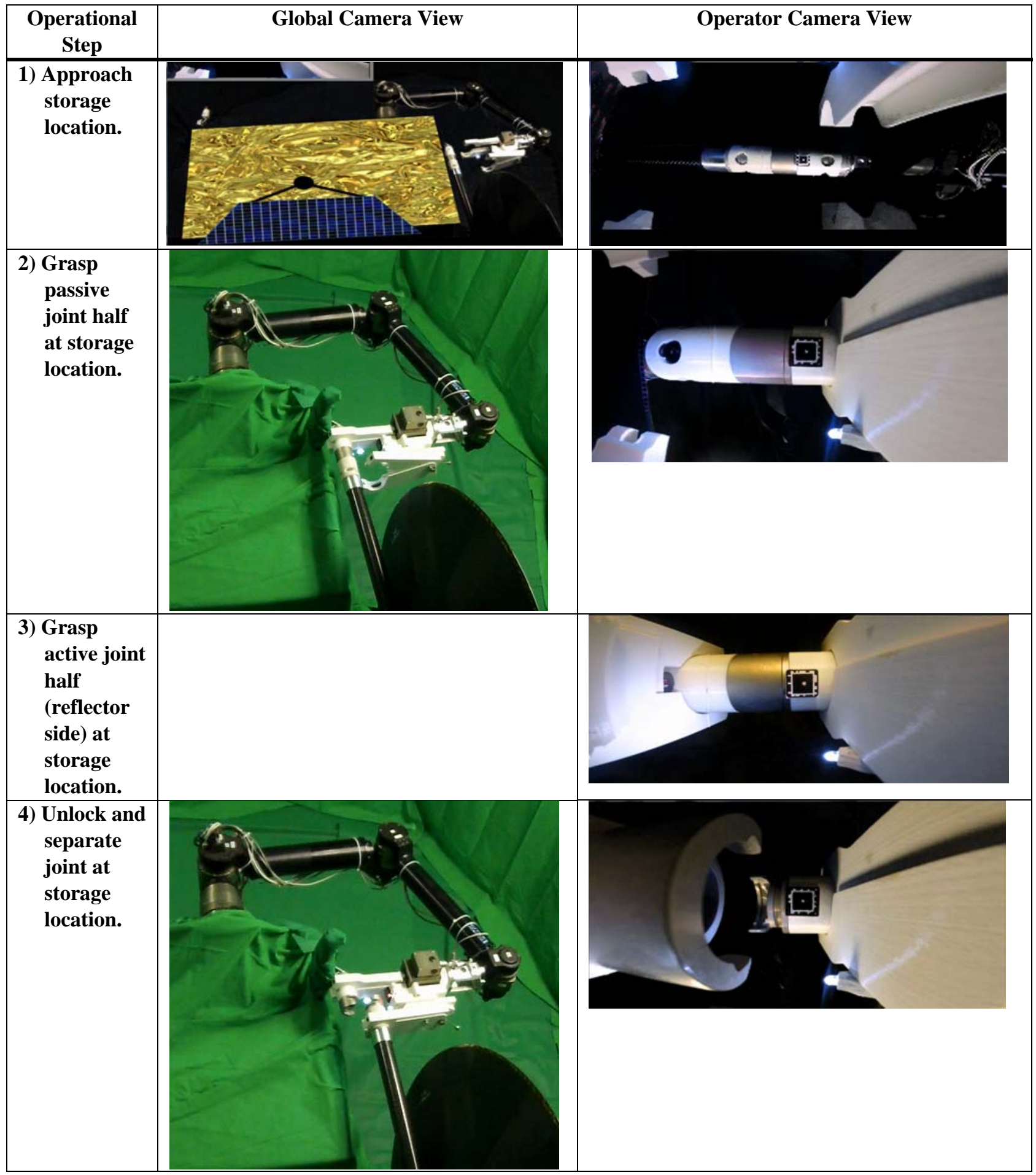


Table 3, Steps for installing a reflector on orbit (continued).

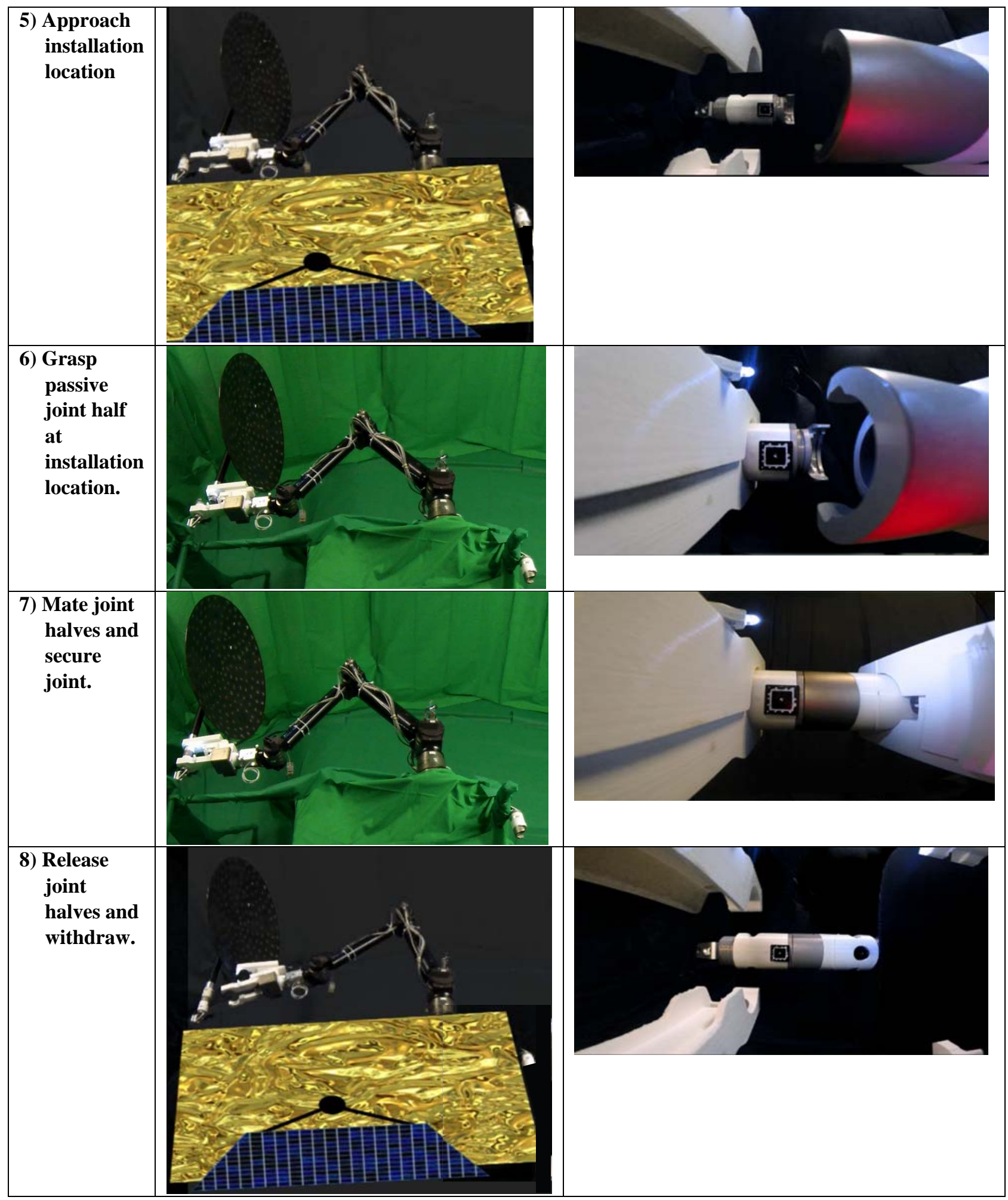




\section{Closing comments.}

In-space assembly (ISA) enables a variety of alternate deployment strategies to be exploited for spacecraft, ranging from more compact packaging on a single launch vehicle to integration and assembly of multiple payloads from separate launch vehicles. Even for the case of a single launch, ISA provides a competitive advantage over conventional deployment strategies, enabling a doubling of the telecommunication bandwidth without impacting launch volume constraints. The approach presented here builds on decades of experience developed within the National Aeronautics and Space Administration and Defense Advanced Research Projects Agency (DARPA) on assembly strategies, space robotic systems, and joining technologies. The Dragonfly study funded by DARPA's Tactical Technology Office has shown the viability of applying ISA to the commercial market as a first step toward making ISA an accepted operational approach for commercial in-space operations.

\section{Acknowledgements}

The authors would like to thank Gordon Roesler and Michael Renner of DARPA TTO for their insights and guidance during the Dragonfly Study Program.

\section{References}

${ }^{1}$ Henshaw, Carl Glen, "The DARPA phoenix spacecraft servicing program: Overview and plans for risk reduction," International Symposium on Artificial Intelligence, Robotics and Automation in Space (i-SAIRAS), 2014.

${ }^{2}$ Rhodes, Marvin D., Ralph W. Will, and Wise, Marion A., "A telerobotic system for automated assembly of large space structures,” (1989).

${ }^{3}$ Patten, L., Evans, L., Oshinowo, L., Ochisor, M., Kazuharu, N., Lodewijk, A., Tabarah E., "International Space Station Robotics, A Comparative Study of ERA, JEMRMS and MSS $7^{\text {th }}$ ESA Workshop on Advanced Space Technologies for Robotics and Automation,” ASTRA 2002 ESTEC, Noordwijk, the Netherlands, November 19 - 21, 2002.

${ }^{4}$ Evans, Lindsay, “Canadian Space Robotics on Board the International Space Station,” 2005 CCToMM Symposium on Mechanisms, Machines, and Mechatronics, Canadian Space Agency, Montreal, Canada, 2005, pp. 26-27.

${ }^{5}$ Sallaberger, Christian, Space Plan Task Force, and Canadian Space Agency, “Canadian space robotic activities," Acta Astronautica 41.4 (1997), pp. 239-246.

${ }^{6}$ Heard Jr, Walter L., and Watson, Judith J., "Results of the access space Construction Shuttle Flight Experiment," $2^{\text {nd }}$ Aerospace Maintenance Conference, 1986, pp. 118-24.

${ }^{7}$ Anon., "Technology for Large Space Systems: A Bibliography with Indexes,” NASA SP-7046, September 1989.

${ }^{8}$ Bush, Harold G., et al., "Design and fabrication of an erectable truss for precision segmented reflector application," Journal of Spacecraft and Rockets 28.2 (1991), pp. 251-257.

${ }^{9}$ Mikulas Jr, Martin M., and Dorsey, John T., “An integrated in-space construction facility for the 21st century,” (1988).

${ }^{10}$ Mikulas, Martin M. Jr., et al., "Space station truss structures and construction considerations,” (1985).

${ }^{11}$ Mikulas, Martin M., Collins, Timothy J., Doggett, William, Dorsey, John, and Watson, Judith, "Truss Performance and Packaging Metrics," American Institute of Physics (AIP) Conference Proceedings, Volume 813, Editor Mohamed S. El-Genk, 2006.

${ }^{12}$ Lake, Mark S., "Launching a 25-Meter Space Telescope, Are Astronauts a Key to the Next Technically Logical Step After NGST?,” Presented at the 2001 IEEE Aerospace Conference, IEEE Proceedings, Volume 7, Paper No. 460.

${ }^{13}$ Heard, Walter L., Jr., Bush, Harold G., and Watson, Judith J., “Space Truss Construction Studies,” ASCE Space 88 Engineering, Construction, and Operations in Space Conference, Albuquerque, NM, August 29-31, 1988.

${ }^{14}$ Heard Jr, Walter L., et al., "Tests of an alternate mobile transporter and extravehicular activity assembly procedure for the Space Station Freedom truss,” NASA TP 3245, October 1992.

${ }^{15}$ Heard, Walter L., Jr., Bush, Harold G., Wallsom, Richard E., and Jensen, J. Kermit, “A Mobile Work Station Concept for Mechanically Aided Astronaut Assembly of Large Space Structures,” NASA TP 2108, March 1983.

${ }^{16}$ Watson, Judith J., Collins, Timothy J., and Bush, Harold G., "A History of Astronaut Construction of Large Space Structures at NASA Langley Research Center,” IEEE Aerospace Conference Proceedings, Volume 7, 2002, pp. 3569-3587, Paper 390. 
${ }^{17}$ Bush, Harold G., Mikulas, Martin M., and, Wallsom, Richard E., "Mechanical End Joint System for Connecting Structural Column Elements,” United States Patent Number: 4,963,052, Date of Patent: October 16, 1990.

${ }^{18}$ Watson, Judith J., Heard, Walter L., Jr., and Jensen, J. Kermit, "Swing-Arm Beam Erector (SABER) Concept for Single Astronaut Assembly of Space Structure,” NASA TP 2379, March 1985.

${ }^{19}$ Heard, Walter L., Jr., Bush, Harold G., and Watson, Judith J., "Space Truss Construction Studies,” ASCE Space 88 Engineering, Construction, and Operations in Space Conference, Albuquerque, NM, August 29-3, 1988.

${ }^{20}$ Heard, Walter Jr., Bush, Harold, Watson, Judith, Spring, Sherwood, and Ross, Jerry, “Astronaut/EVA construction of Space Station," AIAA Structural Dynamics and Materials Issues of the International Space Station, Conference, Williamsburg, VA, April 21-22, 1988, AIAA 88-2459.

${ }^{21}$ Heard, Walter L., and Lake, Mark S., "Neutral buoyancy evaluation of extravehicular activity assembly of a large precision reflector,” Journal of Spacecraft and Rockets 31.4 (1994), pp. 569-577.

${ }^{22}$ Lake, Mark S., Heard, Walter L., Watson, Judith J, and Collins, Timothy J., "Evaluation of Hardware and Procedures for Astronaut Assembly and Repair of Large Precision Reflectors,” (2000).

${ }^{23}$ Bush, Harold G., et al., "Design and fabrication of an erectable truss for precision segmented reflector application,” Journal of Spacecraft and Rockets 28.2 (1991), pp. 251-257.

${ }^{24}$ Dorsey, John T., and Watson, Judith J., "Summary of LaRC 2-inch Erectable Joint Hardware Heritage Test Data," NASA TM 2016-219189.

${ }^{25}$ Will, R. W., and Rhodes, M. D., “An automated assembly system for large space structures,” SPIE Symposium on Advances in Intelligent Systems, Cooperative Intelligent Robotics in Space, 1990.

${ }^{26}$ Doggett, William R., "A Guidance Scheme for Automated Tetrahedral Truss Structure Assembly Based on Machine Vision,” NASA Technical Paper 3601. 